\title{
Influence of Production Parameters on the Properties of 3D Printed Magnesium Alloy Mg- 4Y-3RE-Zr (WE43)
}

\author{
Patrícia Krištofová ${ }^{1}$, Michaela Roudnická ${ }^{1}$, Jiří Kubásek ${ }^{1}$, David Paloušek ${ }^{2}$, Jan Suchý ${ }^{2}$, Dalibor Vojtěch ${ }^{1}$ \\ ${ }^{1}$ Faculty of Chemical Technology, Department of Metals and Corrosion Engineering, University of Chemistry and \\ Technology Prague, Technická 5, 16628 Praha 6 - Dejvice, Czech Republic. E-mail: Patricia.Kristofova@vscht.cz, \\ Michaela.Roudnicka@vscht.cz, Jiri.Kubasek@vscht.cz, Dalibor.Vojtech@vscht.cz \\ ${ }^{2}$ Faculty of Mechanical Engineerinng, Institute of Machine and Industrial Design, Brno University of Technology, \\ Technická 2896/2, 61669 Brno, Czech Republic. E-mail: palousek@fme.vutbr.cz, Jan.Suchy1 @ vut.cz
}

This paper reports on the influence of production parameters on the properties of 3D printed magnesium alloy Mg-4Y-3RE-Zr (WE43) produced by the selective laser melting method. We present microstructures and mechanical properties of four selected samples prepared under various production parameters. Optical and scanning electron microscopy together with energy-dispersive X-ray spectrometry were used for microstructure analysis. Porosity was evaluated based on image analysis. To represent differences in mechanical properties, microhardness measurement and compression tests were performed. Based on our observations of microstructure quality and performed tests, the results of the parameter impact study are further applied to the production of products of the required quality.

Keywords: Magnesium, WE43, Production parameters, Properties, Selective Laser Melting

\section{Introduction}

3D printing, also known as 'additive manufacturing', is used predominantly for the production of lightweight parts in the aerospace, automotive or cosmic industries. $3 \mathrm{D}$ printing can be also found in medicine, specifically for the production of bone and joint replacements exactly according to the CT data or magnetic resonance of the damaged tissue, and also for the production of implant prototypes that enable the operators with a consultation prior to surgery and contribute to its subsequent troublefree operation. The input information for 3D printing is a $3 \mathrm{D}$ model of the desired product designed in a CAD computer program, which is then virtually cut into individual layers which will be printed layer by layer $[1,2]$.

The selective laser melting (SLM) method works on the principle of complete melting of a powder material. The construction of a product begins on a base plate onto which the powder is deposited from a storage reservoir in the form of a thin layer of precisely defined thickness. Subsequently, each powder layer is melted by means of a laser whose movement and other parameters (e.g. scanning speed, laser power, hatch distance) are precisely defined in the control program. Due to high thermal gradients, the melt solidifies rapidly when the beam is shifted further. Once the layer is melted, the base plate is moved by the thickness of one layer downward and another powder is deposited from the reservoir. The process repeats until all the powder constituting the final product is melted and solidified in a compact material. Excess powder is removed from the working chamber after 3D printing is complete and the product is separated from the base plate. To prevent the oxidation of the material, an inert gas - argon or nitrogen - must be fed into the working chamber. The whole production process is shown in Fig. $1[3,4]$.
Magnesium and their alloys are ones of the most used metallic materials due to their low density and good mechanical strength. A few years ago, the most widespread magnesium alloys of the AZ type were alloyed with aluminum and zinc. However, due to the constant pressure to improve the properties of the materials, magnesium alloys with rare earth elements (Mg-RE) have been developed. These alloys have increased mechanical stability and withstand temperatures up to 250 degrees due to the ability of RE elements to form stable precipitates in the magnesium matrix. WE43 is one of Mg-RE alloys which is characterized not only by thermal stability, but also by good strength, biocompatibility and enhanced corrosion resistance $[5,6]$. The biocompatibility of magnesium allows also the application of magnesium alloys in medicine. Because magnesium dissolves in the aggressive environment of body fluids, it is intended for biodegradable implants (mainly stents) which fulfill their supporting role only temporary and are gradually replaced by natural tissue. However, corrosion of pure magnesium is very fast for such application. Rare earth elements (RE) (such as Y, Nd, Gd, and Dy) by which magnesium is alloyed in the WE43 alloy are responsible for reducing the corrosion rate of magnesium to a suitable level. $[5,7,8]$.

The 3D printing of WE43 alloy could offer a great asset in the field of biodegradable implants and some other interesting applications. However, its processing by laser melting is challenging due to the high affinity of magnesium to oxygen and low boiling temperature. So far, only a limited number of papers have dealt with this material $[9,10,11,12]$. In this study, we present the influence of SLM production parameters on the quality of WE43 samples, especially in terms of relative density and its impact on mechanical properties. 


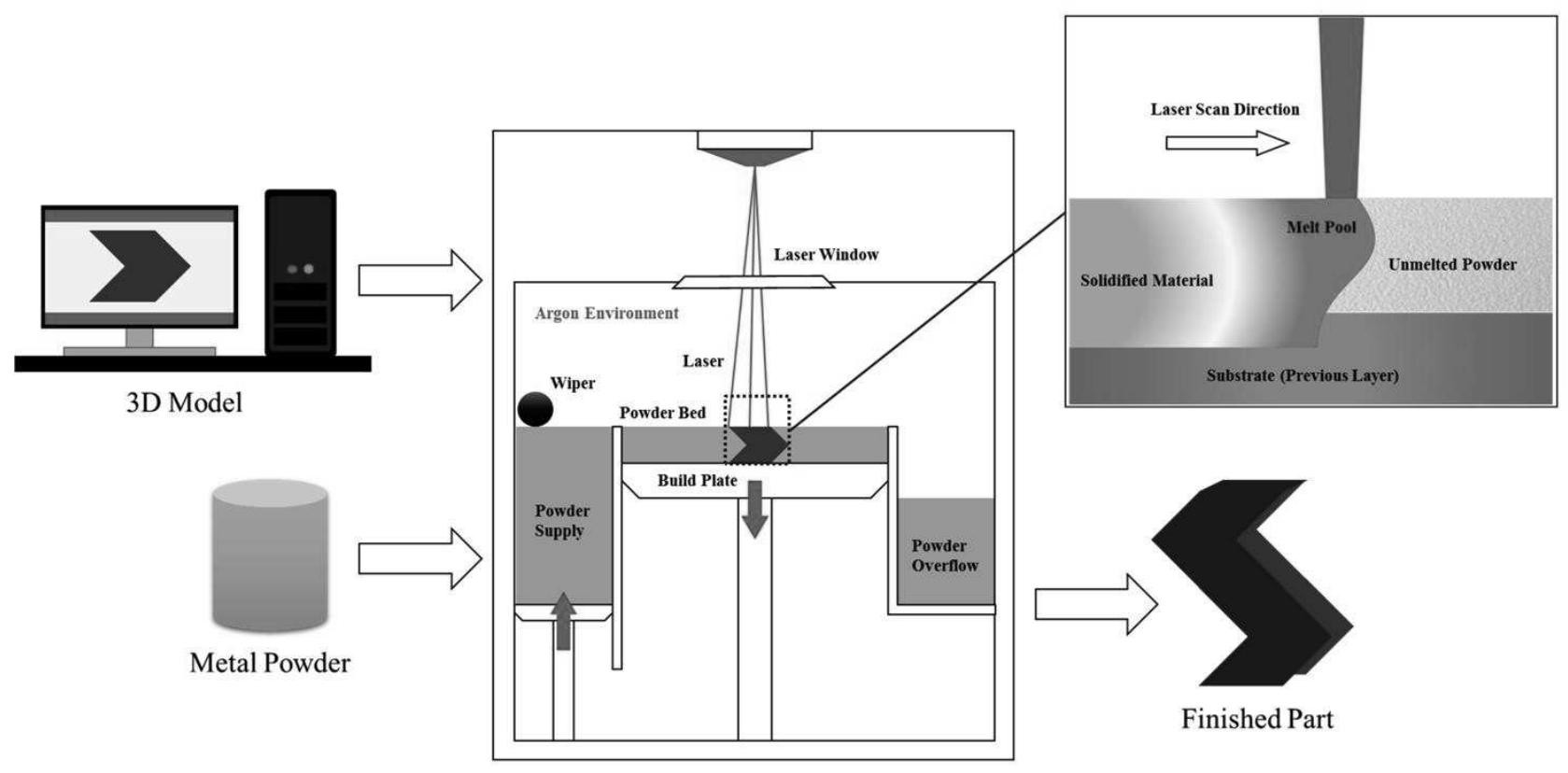

Fig. 1 Selective Laser Melting scheme [13]

\section{Experimental Procedure}

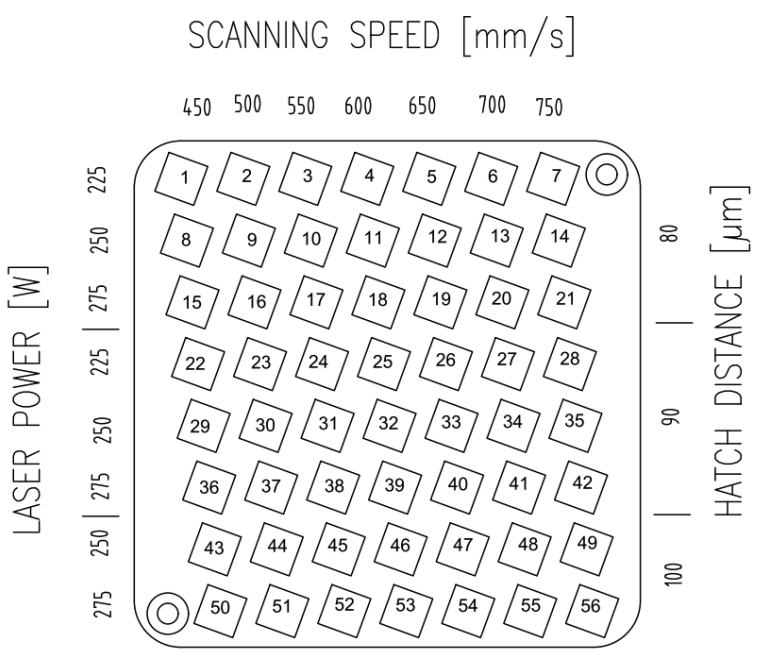

Fig. 2 Matrix of production parameters of individual samples

The material tested in our study was a magnesium alloy WE43 (Mg-4Y-3RE-Zr) prepared by the SLM 3D printing process on the SLM Solution $280 \mathrm{HL}$ machine (SLM Solutions AG, Lübeck, Germany) eguipped with 400W YLR- Laser (IPG Photonics, Oxford, MA, USA) working in a continuous wave mode. For the experiment

Tab. 1 SLM parameters of produced samples

Tab. 1 SLM parameters of produced samples
\begin{tabular}{|c|c|c|c|}
\hline Sample number & Laser power $(\mathbf{W})$ & Scanning speed $(\mathbf{m m} / \mathbf{s})$ & Hatch distance $(\boldsymbol{\mu m})$ \\
\hline 8 & 250 & 450 & 80 \\
\hline 13 & 250 & 700 & 80 \\
\hline 36 & 275 & 450 & 90 \\
\hline 41 & 275 & 700 & 90 \\
\hline
\end{tabular}

of production parameters optimization, a matrix of $56 \mathrm{di}$ fferent parameter settings was designed. The changing parameters were laser power $(225-275 \mathrm{~W})$, scanning speed $(450-750 \mathrm{~mm} / \mathrm{s})$ and hatch distance $(80-100 \mu \mathrm{m})$ (Fig. 2). The beam focus diameter was $82 \mu \mathrm{m}$. Layer thickness was $50 \mu \mathrm{m}$. A total of 56 cube-shaped samples with an $8 \mathrm{~mm}$ edge (Fig. 3) were produced. All samples were manufactured in Argon 5.0 high purity inert athmospere.

To describe the effects of changing production parameters on porosity, microstructure and mechanical properties, 4 samples are selected in this paper; specifically, samples nos. 8, 13, 36 and 41 . The parameters that were used to produce these samples are listed in Tab. 1.

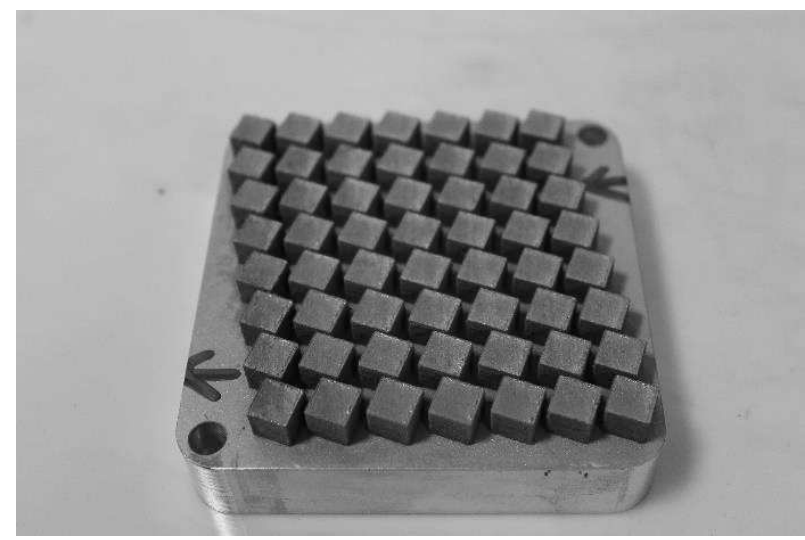

Fig. 3 Build plate with the samples produced by SLM 
The impact of process parameters was observed on sample porosity first. Porosity was determined by means of image analysis (ImageJ program) of metallographic sections prepared by a standard metallographic way. The samples were ground on SiC papers up to P2500 roughness. Subsequently, the samples were polished on a diamond paste with a grain size of $0.2 \mu \mathrm{m}$ and finally the samples were polished on Etosil E. The microstructure of the samples was monitored using an OLYMPUS PME-3 light microscope followed by a TESCAN VEGA 3 LMU scanning electron microscope equipped with a dispersive spectrometer (OXFORD Instruments INCA 350). Porosity was established from low-magnification images, microstructure was then observed at higher magnification. The effect of production parameters on the mechanical properties was observed too. The hardness of the samples was measured by the Vickers hardness test (ČSN EN ISO 6507-1) using a Future-Tech FM-700 microhardness tester with a load of $100 \mathrm{~g}$ at a dwell of $10 \mathrm{~s}$. Mechanical testing in compression (ČSN EN ISO 604) was performed with a LabTest 5.250SP1-VM universal loading machine. For the compression tests, cubic samples were used. The deformation rate was set to $0.001 \mathrm{~s}^{-1}$.

\section{Results and Discussion}

\subsection{Microstructure and porosity}

Fig. 4 shows micrographs of the four studied samples along with the composed images of the whole cross-sections that were used for the image analysis of porosity. There are obvious differences in the porosity of individual samples apparent on the cross-sections. In Tab. 2, the values of porosity measured by the image analysis are shown. The best result of sample production by SLM was obtained with the setting of production parameters for the sample no. 8 (Tab. 1). This sample showed porosity of only $0.2 \%$. Most porosity was located in the uppermost part of the sample. Compared to the sample no. 8, samples nos. 13, 36 and 41 showed porosity of $1 \%$ and higher.

Multiple mechanisms of pore formation are possible during the SLM of WE43 magnesium alloy. We mostly observe imperfect bonding between layers. It can be associated not only with insufficient energy density but also with the affection by oxygen. Energy density is the amount of energy given to a volumetric unit of the powder material. In a simplified form, it can be calculated from the values of laser power $(P)$, scanning speed $(v)$, hatch distance $(h)$ and layer thickness $(t)$ according to the following formula [14]:

$$
E=\frac{P}{v h t}\left[J \mathrm{~mm}^{-3}\right]
$$

Each material needs an optimal amount of energy for proper consolidation. If the energy is insufficient, successively processed layers or even tracks within one layer do not fuse properly. Conversely, if the energy is too high, melt becomes unstable, material evaporates, and pores are formed. Based on the minimal porosity of the sample no. 8 , it can be concluded that the optimal energy density lies around $140 \mathrm{~J} / \mathrm{mm}^{3}$. As the energy density is inversely proportional to scanning speed and hatch distance, the energy density was lower for other samples for which those parameters were increased. High scanning speed of 700 $\mathrm{mm} / \mathrm{s}$ for samples nos. 13 and 41 yielded insufficient $\mathrm{E}$. At this higher speed, a shorter contact of the laser with the powder resulted in the lower amount of the melt and so insufficient interconnection between individual layers. A layered structure with imperfectly bonded layers is thus apparent in both samples (Fig. 4). Even though the scanning speed seems to play the key effect, the hatch distance also influences the melting process when the scanning speed is constant. For the production of sample no. 36, laser power and hatch distance were increased compared to the sample no. 8 while scanning speed remained constant. Such a simultaneous change in $P$ and $h$ caused $E$ to become almost unchanged $\left(136 \mathrm{~J} / \mathrm{mm}^{3}\right)$. Despite that, we observe improper interconnection between some layers (Fig. 4) and a porosity value of $1 \%$. Here, the higher $h$ is probably the cause. Due to the higher spacing between adjacent scan tracks, the melt did not fuse properly [14, $15]$.

In the sample no. 8, a different type of pores was observed. Rather spherical voids appeared in the uppermost part of the sample. These voids can be attributed to the so-called keyhole effect. With more and more layers, the heat accumulates, and, in some point, the melt may be no longer stable, material starts to evaporate, and the vapour is then trapped in a rather spherical void which remain in the solidified structure.

Tab. 2 Values of measured porosity

\begin{tabular}{|c|c|}
\hline Sample & Porosity (volume \%) \\
\hline 8 & 0.2 \\
\hline 13 & 1.5 \\
\hline 36 & 1.0 \\
\hline 41 & 3.5 \\
\hline
\end{tabular}

The scanning microscope images obtained in the regime of back scattered electrons in Fig. 5 show that the material is relatively heavily contaminated with oxygen. Light areas in the microstructure were determined by the XRD phase analysis and EDS element distribution maps to be oxides, mainly $\mathrm{Y}_{2} \mathrm{O}_{3}$. The content of oxides was in the order of volume $\%$. The origin of oxides can be found in the oxide shells of powder particles, but the oxides content can be also enhanced by further oxidation during the SLM process in the protective atmosphere which always contains some oxygen residues. We can observe a clear difference in the distribution of oxides in the microstructure between the samples nos. 8,36 and 13,41. In the samples nos. 8 and 36 which are associated with higher energy density, the oxide shells are disintegrated into smaller particles and are homogeneously distributed in the matrix. Compared to that, oxide shells covering individual powder particles can be seen in the microstructure of samples nos. 13 and 41, in which the energy was not sufficient, and the powder particles were not melted completely. 

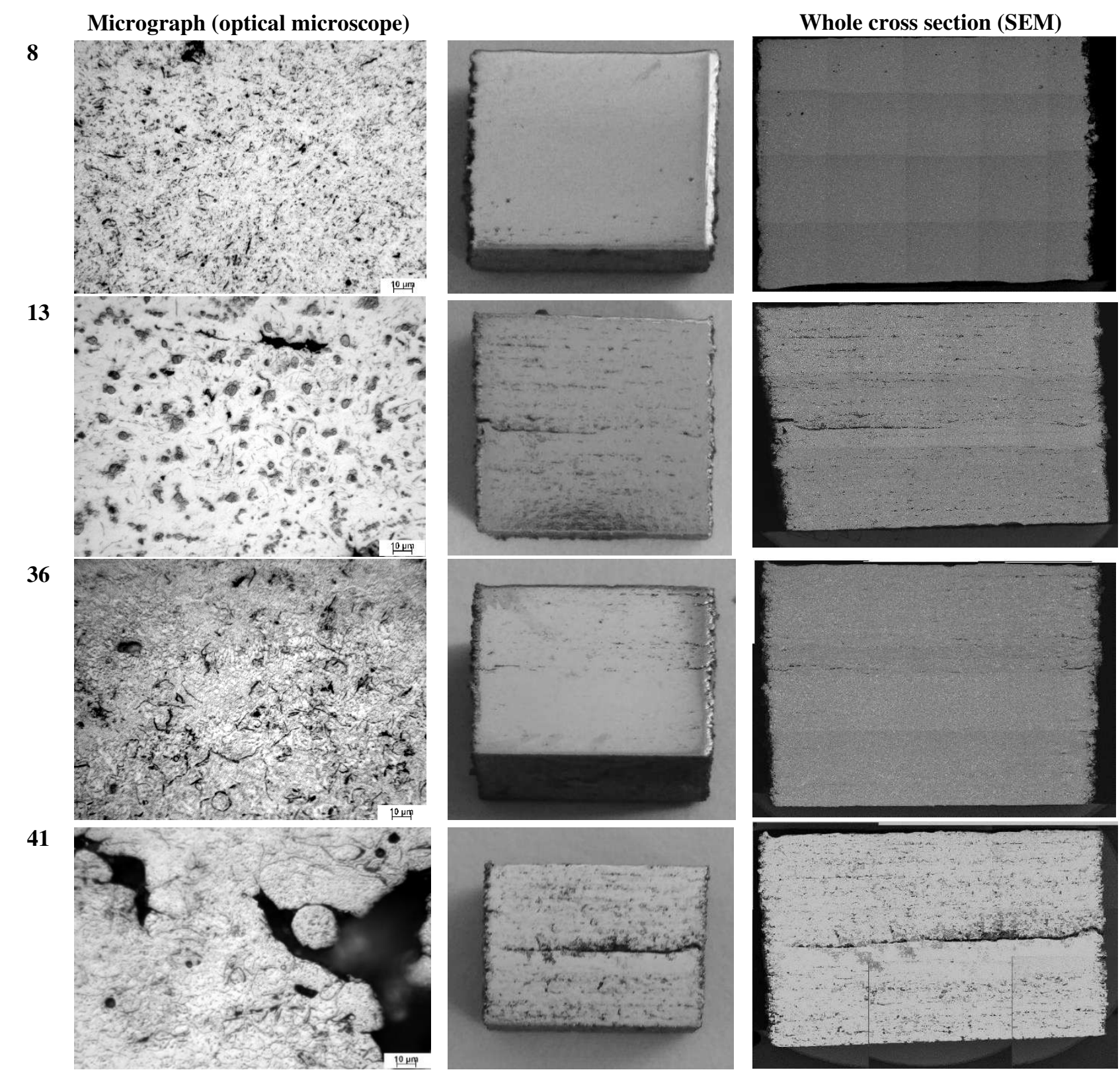

Fig. 4 Macrostructure of the studied samples, photo of optical microscope (3D printing direction from bottom to top)
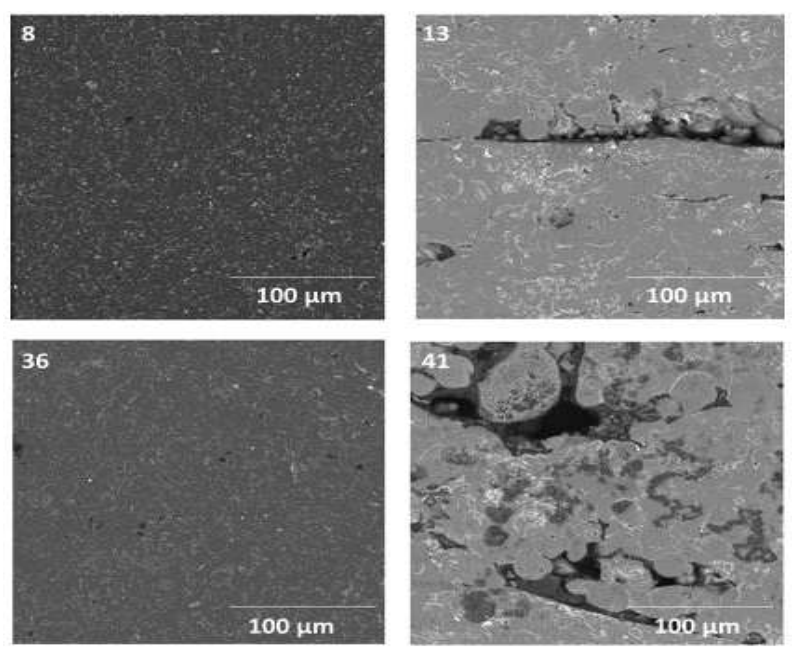

Fig. 5 SEM micrographs of the WE43 alloy printed by the SLM method - samples nos. 8, 13, 36 and 41

\section{Mechanical properties}

Tab. 3 shows the microhardness values of the examined samples. There is not a significant difference between individual samples, suggesting that the production parameters and related energy does not influence the microstructure evolution while they have a significant effect on porosity. The microstructure evolution is mainly dictated by the rapid cooling during SLM.

Tab. 3 Vickers hardness HVO.1 (average from 10 measurements)

\begin{tabular}{|c|c|c|c|c|}
\hline sample & 8 & 13 & 36 & 41 \\
\hline HV0.1 & $88 \pm 6$ & $85 \pm 6$ & $86 \pm 6$ & $81 \pm 7$ \\
\hline
\end{tabular}

Significant differences in porosity of individual samples resulted in a different response to mechanical loading (see stress-strain curves in Fig. 6). The measured values of yield strength and compressive strength (Tab. 
4) correspond with porosity. More porous materials (samples nos. 13, 41) are generally characterized by lower compressive strength compared to materials of lower porosity (samples nos. 8, 36).

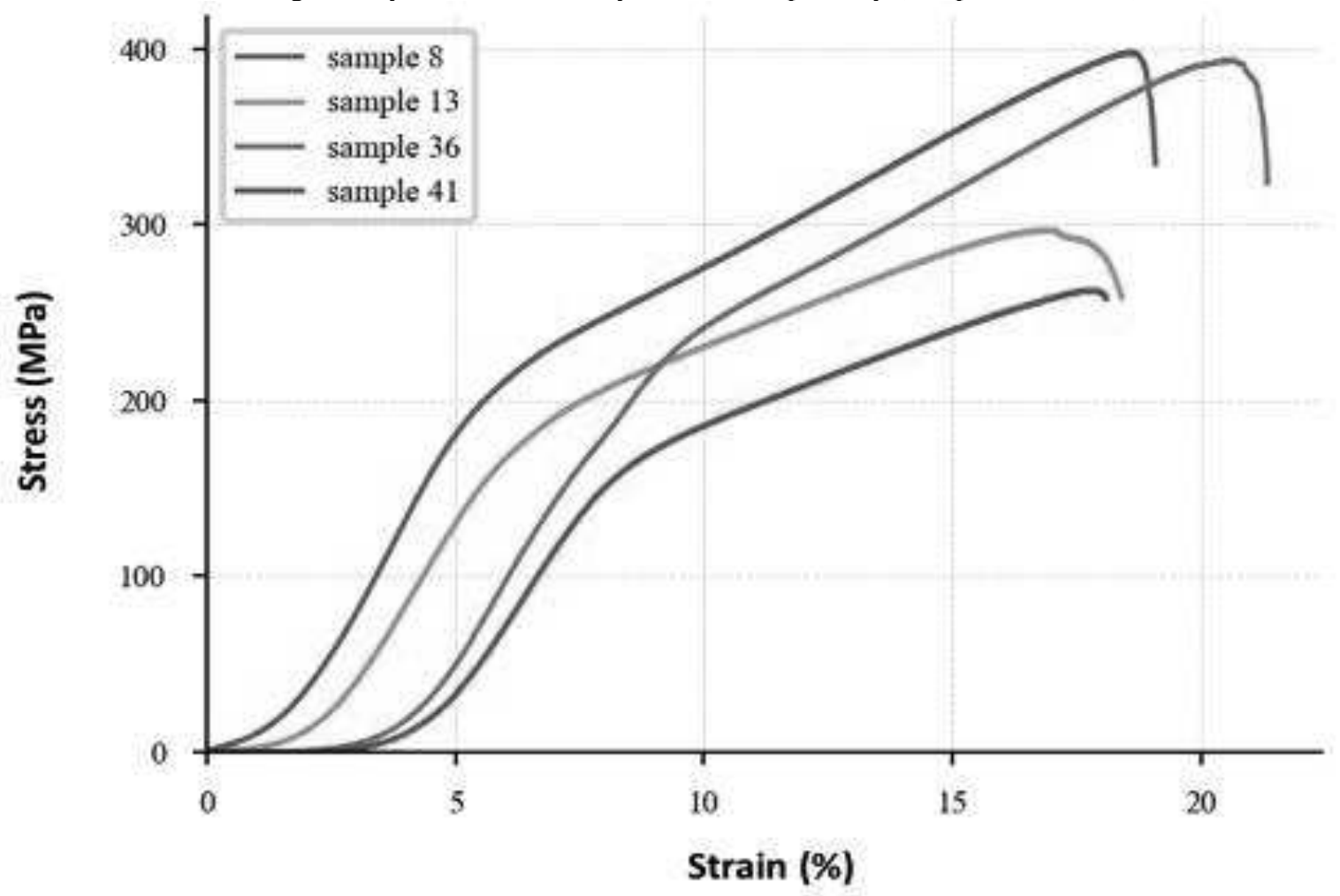

Fig. 6 Compressive stress-strain curves of WE43 3D printed alloy samples

Tab. 4 Results of compression tests

\begin{tabular}{|l|c|c|c|c|}
\hline Sample & $\mathbf{8}$ & $\mathbf{1 3}$ & $\mathbf{3 6}$ & $\mathbf{4 1}$ \\
\hline Compressive yield strength (MPa) & 208 & 175 & 220 & 165 \\
\hline Ultimate compressive strength (MPa) & 395 & 296 & 386 & 261 \\
\hline
\end{tabular}

Tab. 5 shows a summary of all measurements at given manufacturing parameters. It is clear that the parameters affect mainly porosity, which is then reflected in the mechanical properties. Based on the results of the compression tests, it is clear that more rigid structure of the material can be achieved with the lower scanning speed (450 $\mathrm{mm} / \mathrm{s})$. It is because at the lower speed, the laser has enough time to fully melt each layer and interconnect it with the previous one. If the scanning speed is higher (such as for samples nos. 13 and 41), the laser stays in one place for a shorter time, which reduces the melt volume and so makes the material fusion less sufficient, yielding in higher porosity.

Tab. 5 Summary table of all measurements

\begin{tabular}{|c|c|c|c|c|}
\hline Sample & $\mathbf{8}$ & $\mathbf{1 3}$ & $\mathbf{3 6}$ & $\mathbf{4 1}$ \\
\hline Laser power $(\mathbf{W})$ & 250 & 250 & 275 & 275 \\
\hline Scanning speed $(\mathbf{m m} / \mathbf{s})$ & 450 & 700 & 450 & 700 \\
\hline Hatch distance $(\boldsymbol{\mu m})$ & 80 & 80 & 90 & 90 \\
\hline Porosity & 0.2 & 1.5 & 1.0 & 3.5 \\
\hline HV0,1 & $88 \pm 6$ & $85 \pm 6$ & $86 \pm 6$ & $81 \pm 7$ \\
\hline Compressive yield strength $(\mathbf{M P a})$ & 208 & 175 & 220 & 165 \\
\hline Ultimate commpressive strength $(\mathbf{M P a})$ & 395 & 296 & 386 & 261 \\
\hline
\end{tabular}

\section{Conclusion}

Our paper has shown that the WE43 alloy can be successfully produced by the progressive technology of Selective Laser Melting although it is a problematic material due to the high reactivity of magnesium. Non-ideal processing atmosphere in SLM with oxygen residues yields the presence of oxides and imperfect consolidation. To reach the highest relative density possible, a proper parameter setting is necessary. We have demonstrated how the change of production parameters (especially scanning speed) can change porosity and so the mechanical properties of the material. Building on this information, the next step will be to produce samples of the required quality and mechanical properties based on suitably selected parameters. 


\section{Acknowledgement}

Authors wish to thank specific university research (MSMT No. 21-SVV/2019) and Ministry of Industry and Trade (project no. FV20232) for the financial support of this research.

\section{References}

[1] RENGIER, F., MEHNDIRATTA, A., TENGGKOBLIGK, H., ZECHMANN, C. M., UNTERHINNINGHOFEN, R., KAUCZOR, H. U., GIESEL, F. L. (2010). 3D printing based on imaging data: review of medical applications, In: International Journal of Computer Assisted Radiology and Surgery, Vol. 5. No. 4, pp. 335-341.

[2] MOHAMMED, M. I., FITZPATRICK, A. P., GIBSON, I. (2017). Customised Design of a Patient Specific 3D Printed Whole Mandible Implant. In: DesTech Conference Proceedings (proceedings of The International Conference on Design and Technology, KEG), pp. 104-111. DOI: http://dx.doi.org/10.18502/keg.v2i2.602

[3] SUFIIAROV, V. S., POPOVICH, A. A., BORISOV, E. V., POLOZOV, I. A., MASAYLO, D. V., ORLOV, A. V. (2016). The effect of layer thickness at selective laser melting. In: Procedia Engineering (proceedings of the 2016 Global Congress on Manufacturing and Management), Vol. 174, pp. 126-134.

[4] OLAKANMI, E., COCHRANE, R. F., DALGARNO, K. W. (2015) Review on selective laser sintering/melting (SLS/SLM) of aluminium alloy powders: Processing, microstructure, and properties. In: Progress in Materials Science, Vol. 74, pp. 401-477.

[5] KRIŠTOFOVÁ, P., KUBÁSEK, J., VOJTĚCH, D., PALOUŠEK, D., SUCHÝ, J. (2019). Microstructure of the Mg-4Y_3RE-Zr (WE43) Magnesium Alloy Produced by 3D Printing. In: Manufacturing Technology, Vol. 19, No. 1, pp. 89-94.

[6] DVORSKÝ, D, KUBÁSEK, J., VOJTĚCH, D., ČAVOJSKÝ, M. (2016). Structure and mechanickal properties of WE43 prepared by powder metallurby route. In: Manufacturing Technology, Vol. 16, No. 5, pp. 896-902.

[7] SEZER, N., EVIS, Z., KAYHAN, S. M., TAHMASEBIFAR, A., KOÇ, M. (2018). Review of magnesium-based biomaterials and their applications. In: Journal of Magnesium and Alloys, Vol. 6, No. 1, pp. 23-43.
[8] DEXUE, L., DONGLIN, Y., XINLING, L., SHIWEN, H. (2019). Mechanical properties, corrosion resistance and biocompatibilities of degradable Mg-RE alloys: A review. In: Journal of Materials Research and Technology, Vol. 8, No. 1, pp. 1538-1549.

[9] GANGIREDDY, S., GWALANI, B., KIU, K., RAIERSON, J. E., MISHRA, S. R. (2019). Microstructure and mechanical behavior of an additive manufactured (AM) WE43-Mg alloy. In: Additive Manufacturing, Vol. 26, pp. 53-64.

[10] TANDON, R., PALMER, T., GIESEKE, M., NOELKE, C., KAIERLE, S. (2016). Additive manufacturing of magnesium alloy powders: Investigations into process development using electron ${ }^{\circledR} \mathrm{MAP}+43$ via laser powder bed fusion and directed energy deposition. Conference Paper: World Powder Metallurgy 2016 Congress and Exhibition, World PM 2016, Hamburg, Germany.

[11] BÄR, F., BERGER, L., JAUER, L., KURTULDU, G., SCHÄUBLIN, R., SCHLEIFENBAUM, H. J., LŐFFLER, F. J. (2019). Laser additive manufacturing of biodegradable madnesium alloy WE43: A detailed microstructure analysis. In: Acta Biomaterialia, Article in Press. https://doi.org/10.1016/j.actbio.2019.05.056.

[12] ZUMDICK, A. N., JAUER, L., KERSTING, C. L., KUTZ, N. T., SCHLEIFENBAUM, H. J., ZANDER, D. (2019). Additive manufactured WE43 magnesium: A comparative study of the microstructure and mechanical properties with those od powder extruded and as-cast WE43. In: Materials Characterization, Vol. 147, pp. 384397.

[13] PATTERSON, A. E., MESSIMER, S. L., FARRINGTON, P. A. (2017). Overhanging Features and the SLM/DMLS Residual Stresses Problem: Review and Future Research Need. In: Technologies, Vol. 5, No. 2, article 15.

[14] READ, N., et al. (2015). Selective laser melting of AlSi10Mg alloy: Process optimisation and mechanical properties development. In: Materials and Design, Vol. 65, pp. 417-424.

[15] HRADIL, D. (2016). Mechanical-structural characteristics of materials produced by SLM method. Master Thesis, Brno University of Technology, Brno, Czech Republic. 